\title{
Rancang Bangun Sistem Informasi Penjualan Online (E-Commerce) pada Toko Cindyah Collection dengan Metode Rapid Application Development
}

\author{
Afan Suriyana, Lukman Junaedi \\ Sistem Informasi, Fakultas Ilmu Komputer, Universitas Narotama Surabaya, \\ J1. Arif Rahman Hakim No. 51, Surabaya 60117, Indonesia \\ 18afansuryana@gmail.com
}

\begin{abstract}
Abstrak
Penelitian ini dilakukan pada Cindyah Collection. Laporan ini diambil dengan judul "Rancang Bangun Sistem Informasi Penjualan Berbasis Web Menggunakan Metode RAD Pada Cindyah Collection". Metode yang digunakan dalam penelitian ini adalah metode RAD (Rapid Application Development) ini dapat dikembangkan sebagai pendekatan yang sangat cocok untuk sistem informasi penjualan. Penelitian ini dilakukan bertujuan untuk membangun sebuah sistem informasi penjualan di Cindyah Collection dan untuk membantu manajamen perusahaan dalam menyediakan penjualan. Sistem informasi penjualan berbasis web ini dibangun menggunakan Freamwork Codeigniter 3.1.0, Php MySql, Xampp, Adobe Illustrator dan Metode Blackbox Testing untuk melakukan pengujian pada sistem. Dengan begitu hasil dari penelitian ini adalah sistem informasi penjualan yang digunakan untuk melakukan transaksi penjualan, pembelian dan pencatatan laporan penjualan yang lebih terkomputerisasi, efisien dan akurat.
\end{abstract}

Kata kunci: Sistem Informasi Penjualan, Freamwork Codeigniter, Php MySql

\section{Pendahuluan (Introduction)}

Pada era globalisasi saat ini, teknologi informasi sangat berperan penting dalam menunjang berbagai macam kegiatan. Teknologi informasi mampu memberikan efektifitas dan keakuratan yang dapat mengorganisir data perusahaan baik dalam jumlah besar serta membantu perusahaan dalam mengambil keputusan dan strategi didalam kebijakan perusahaan. (Yusdiardi, 2014) E-commerce adalah salah satu produk yang dihasilkan oleh internet. (Hasanudin, 2019) Penjualan merupakan suatu usaha yang padu untuk dikembangkan melalui rencana - rencana strategis yang dapat diarahkan pada pemuasan usaha keinginan pembeli dan kebutuhan perusahaan. Penjualan dapat dilakukan dengan berbagai cara yaitu dengan tunai maupun secara kredit. Penjualan adalah salah satu inovasi yang dapat dilakukan secara online dengan berbasis web. (Andriani and Qurniati, 2018)

Cindyah Collection adalah yang bergerak dibidang penjualan semua pakain anak-anak maupun pakaian dewasa. Cindyah Collection memiliki beberapa produk pakaian anak-anak dan pakaian dewasa laki-laki maupun perempuan. Dimana dalam melakukan penjualan dilakukan secara manual sehingga tidak menarik pelanggan. Sistem manual tersebut adalah pegawai melakukan pembayaran penjualannya masih menggunakan kwitansi penjualan sehingga pembuatan laporan menjadi terhambat. Berdasarkan uraian masalah yang ada diatas, maka perlu dibuatkan sistem informasi penjualan yang dapat menyelesaikan masalah yang sudah dijelaskan diatas. Dengan membangun suatu sistem informasi penjualan yang diharapkan akan mampu membantu menyelesaikan berbagai masalah guna mencapai efektifitas dan efisiensi.

\section{Metode Penelitian}

Dalam penelitian ini menggunakan RAD (Rapid Application Development) karena metode ini menggunakan pendekatan berorientasi objek terhadap pengembangan. Dengan menggunakan metode ini juga dapat mempercepat waktu dan biaya di dalam pengerjaanya. RAD dapat juga dikembangkan 
sebagai pendekatan yang cocok untuk sistem informasi penjualan berbasis web. Pada tahap perancangan sistem, metode RAD dapat melibatkan calon pengguna untuk perancanganya. Dalam hal inilah metode RAD memiliki keunggulan karena dapat melibatkan pengguna sistem sehingga sistem yang dihasilkan nanti akan sesuai dengan kebutuhan pengguna sistem tersebut. Kemudian RAD dapat dijadikan sebuah strategi yang mempunyai kecepatan yang dapat melibatkan pengguna dan akan menambah serangkaian dalam sistem yang akhirnya dikembangkan pada sistem yang final.

\subsection{Workshop Desain RAD (Rapid Application Development)}

Merupakan dimana dalam fase ini dapat digambarkan dan dirancang maupun dapat juga diperbaiki. Selama workshop RAD di desain kerja prototype dapat direspon oleh pengguna dan modul-modul yang akan di analisis maupun diperbaiki yang didasari respon penggunanya.

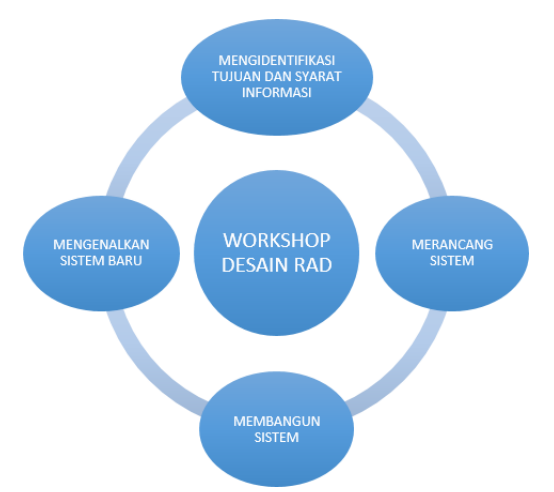

Gambar 1. Workshop Desain RAD

\subsection{Konsep Dasar Penjualan}

Penjualan merupakan suatu usaha yang terpadu untuk mengembangkan rencana strategi yang diarahkan pada pemuasan kebutuhan dan keinginan pembeli, guna mendapatkan penjualan yang menghasilkan keuntungan atau laba. Maka aktifitas penjualan yang dapat dikronologikan sebagai penerimaan pesanan, penegasan pesanan, pengiriman barang, pembuatan faktur, pembuatan laporan penjualan. (Riandya, 2012)

\section{Hasil dan Pembahasan}

Setelah melakukan penelitian dan analisis pada Cindyah Collection, maka diketahui bahwa sistem yang digunakan bersifat semi komputerisasi dimana masih menggunakan Ms. Excel untuk membuat laporan penjualan dan itu akan mengakibatkan waktu yang cukup lama pada prosesnya. Setelah mengetahui sistem yang sedang berjalan maka selanjutnya adalah merancang sistem informasi penjualan berbasis web yang tujuanya untuk memaksimalkan pemasaran produk, meningkatkan angka penjualan dan mempermudah proses pada pembuatan laporan penjualan.

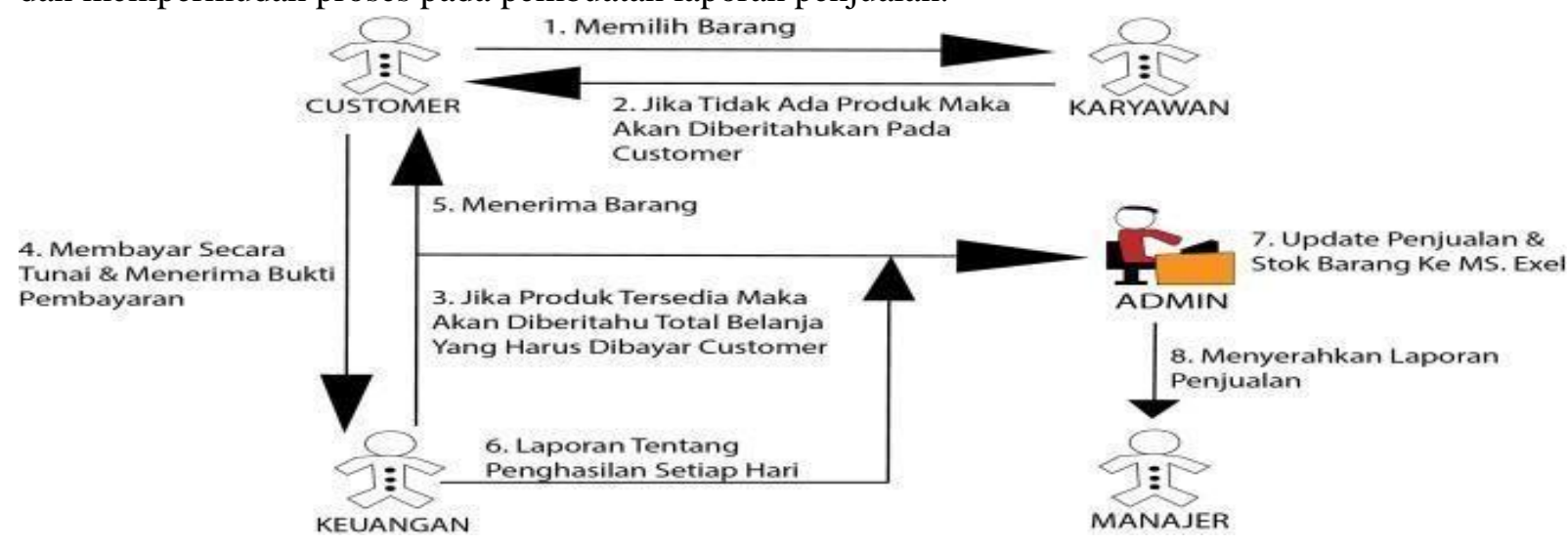

Gambar 2. Analisis sistem yang berjalan 
Ada beberapan usulan prosedur yang tujuanya untuk menyempurnakan sistem yang ada. Dalam merancang dan menganalisa sistem yang diusulkan, peneliti menggunakan tools UML (Unfield Modelling Language) untuk menggambarkan usecase scenario, usecase diagram, activity diagram, sequence diagram dan class diagram.

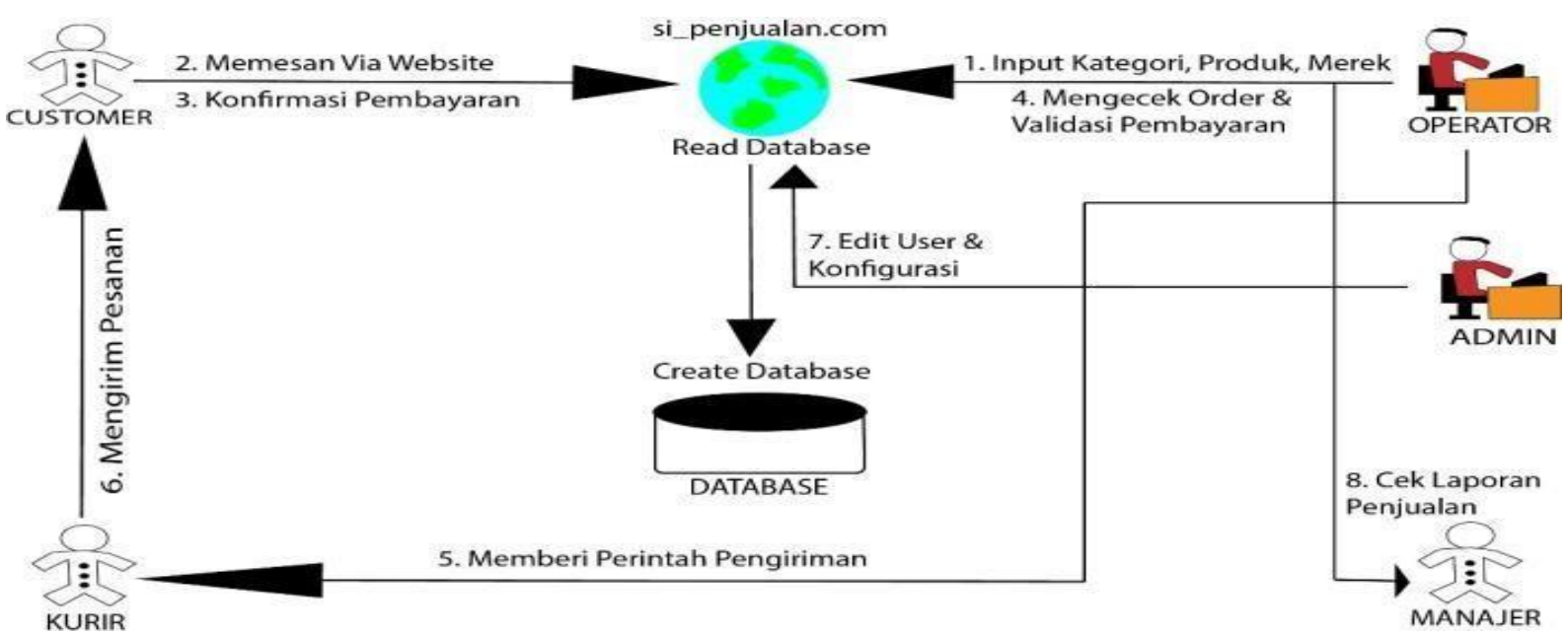

Gambar 3. Analisis sistem yang diusulkan

\subsection{Usecase Diagram}

Pada penelitian ini peneliti menggunakan tools UML (Unfield Modelling Language) untuk menggambarkan sistem yang diusulkan dengan usecase diagram yaitu sebagai berikut:

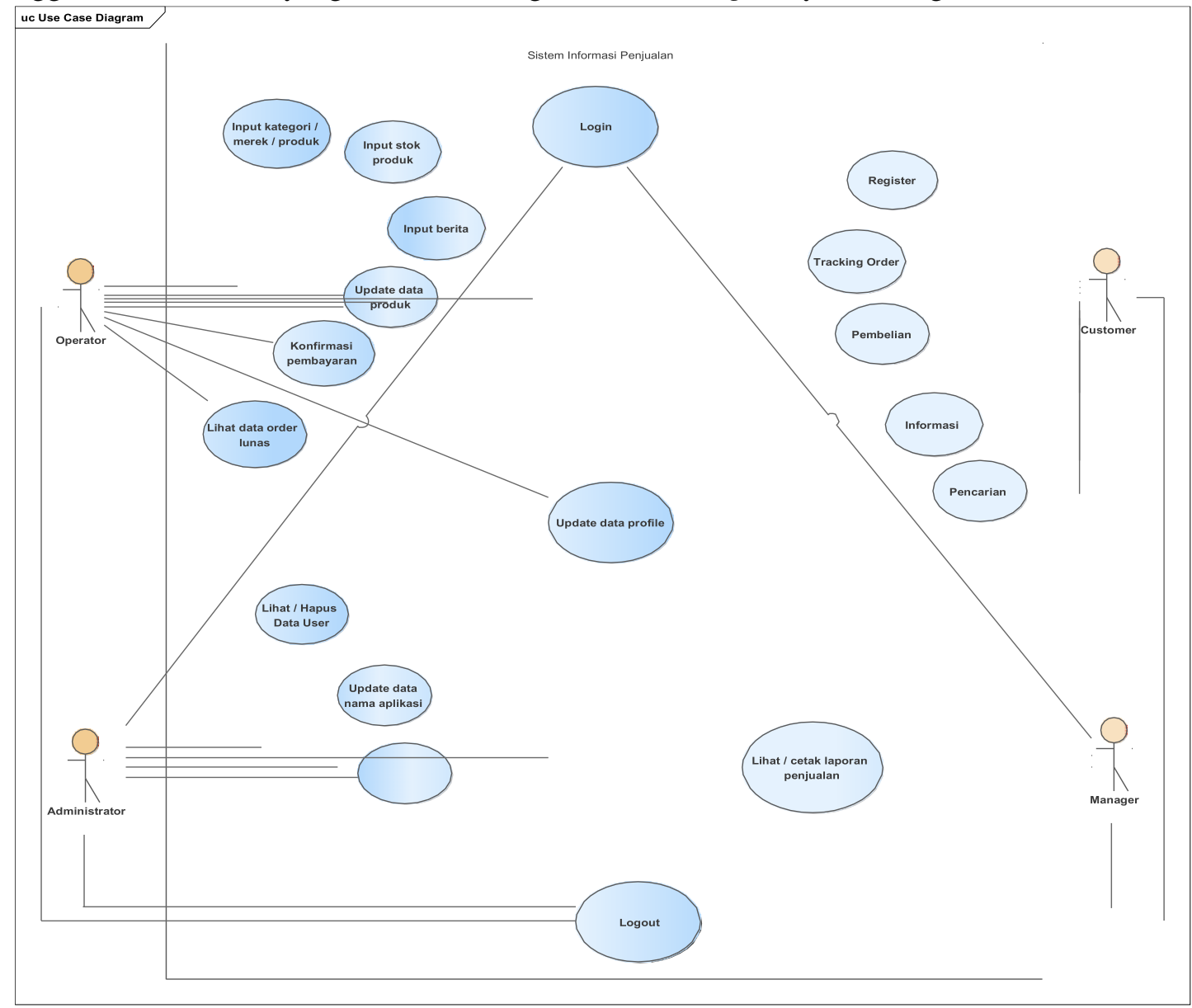

Gambar 4. Use Case Diagram yang diusulkan 
3.2 Usecase Scenario

Ada tampilan usecase scenario login untuk para aktor yaitu sebagai berikut:

\begin{tabular}{|l|l|}
\hline \multicolumn{2}{|c|}{ Identifikasi } \\
\hline No & UD 02 \\
\hline Nama Usecase & Login \\
\hline Tujuan & Masuk kedalam sistem dan dapat mengakses sistem \\
\hline Aktor & Operator, Administrator, Customer \& Manager \\
\hline Deskripsi & Use case ini mendeskripsikan proses login \\
\hline \multicolumn{2}{|c|}{ Skenario Utama } \\
\hline Kondisi Awal & $\begin{array}{l}\text { Operator, administrator, customer \& manager membuka } \\
\text { program kemudian masuk ke menu login }\end{array}$ \\
\hline \begin{tabular}{|l|l|}
\hline \multicolumn{2}{|c|}{} \\
\hline Aksi Aktor
\end{tabular} & $\begin{array}{l}\text { Reaksi Sistem } \\
\text { password }\end{array}$ \\
\hline pemasukkan username dan password & $\begin{array}{l}\text { 3. Menampilkan menu sesuai } \\
\text { level masing - masing }\end{array}$ \\
\hline Kondisi Akhir & $\begin{array}{l}\text { Operator, administrator, customer \& manager dapat } \\
\text { mengakses program }\end{array}$ \\
\hline
\end{tabular}

Gambar 5. Use Case Scenario Login

\subsection{Activity Diagram}

Ada tampilan activity diagram login untuk para aktor sebagai berikut:

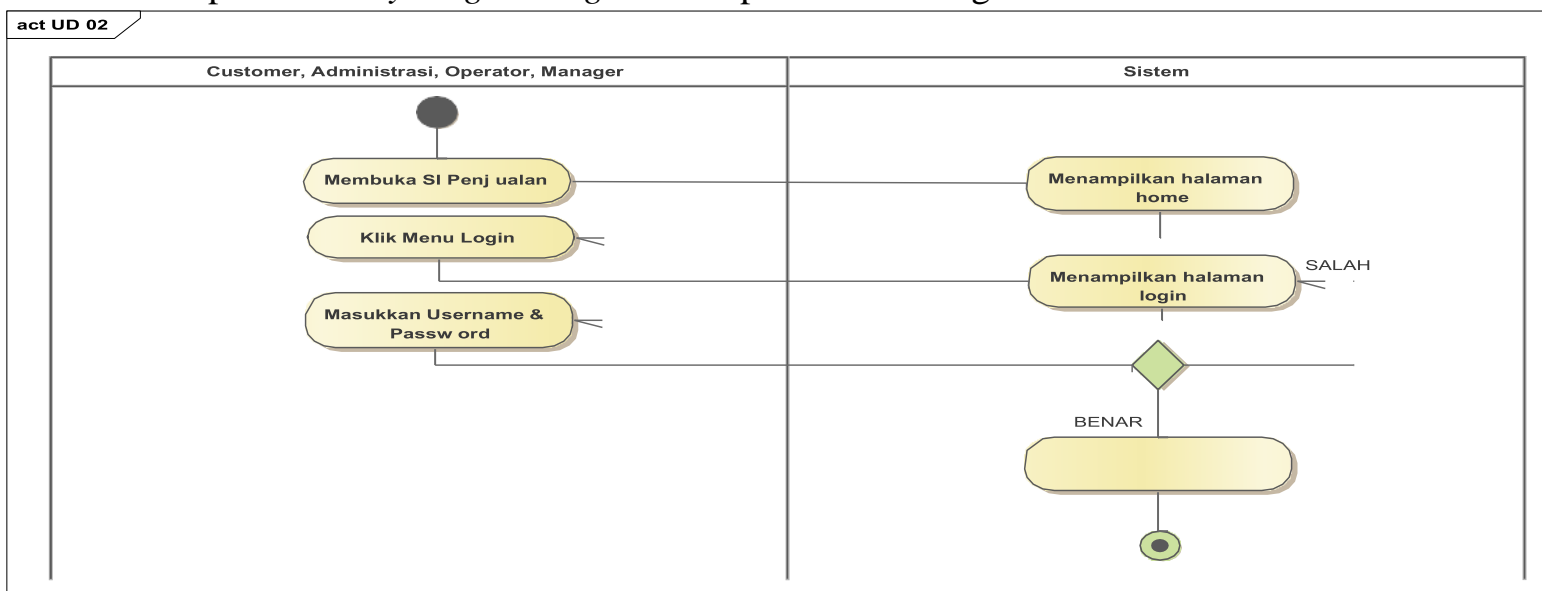

Gambar 6. Activity Diagram Login

\subsection{Sequence Diagram}

Ada tampilan sequence diagram login untuk para aktor sebagai berikut:

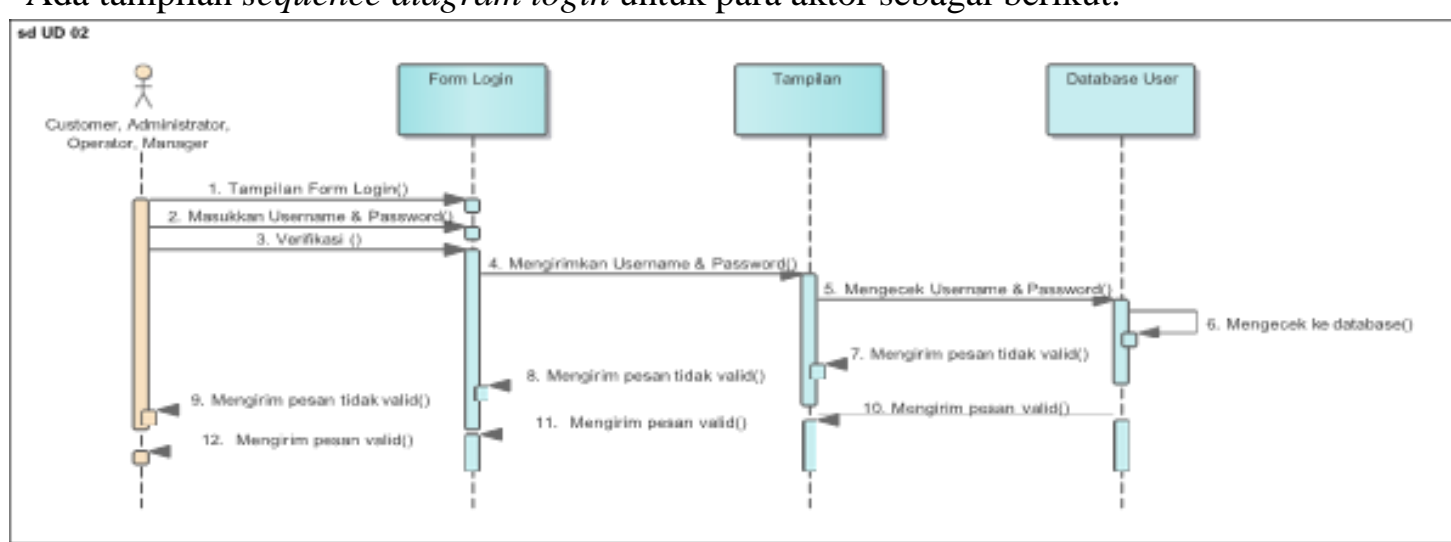

Gambar 7. Sequence Diagram Login 


\subsection{Class Diagram}

Ada tampilan class diagram sebagai berikut:

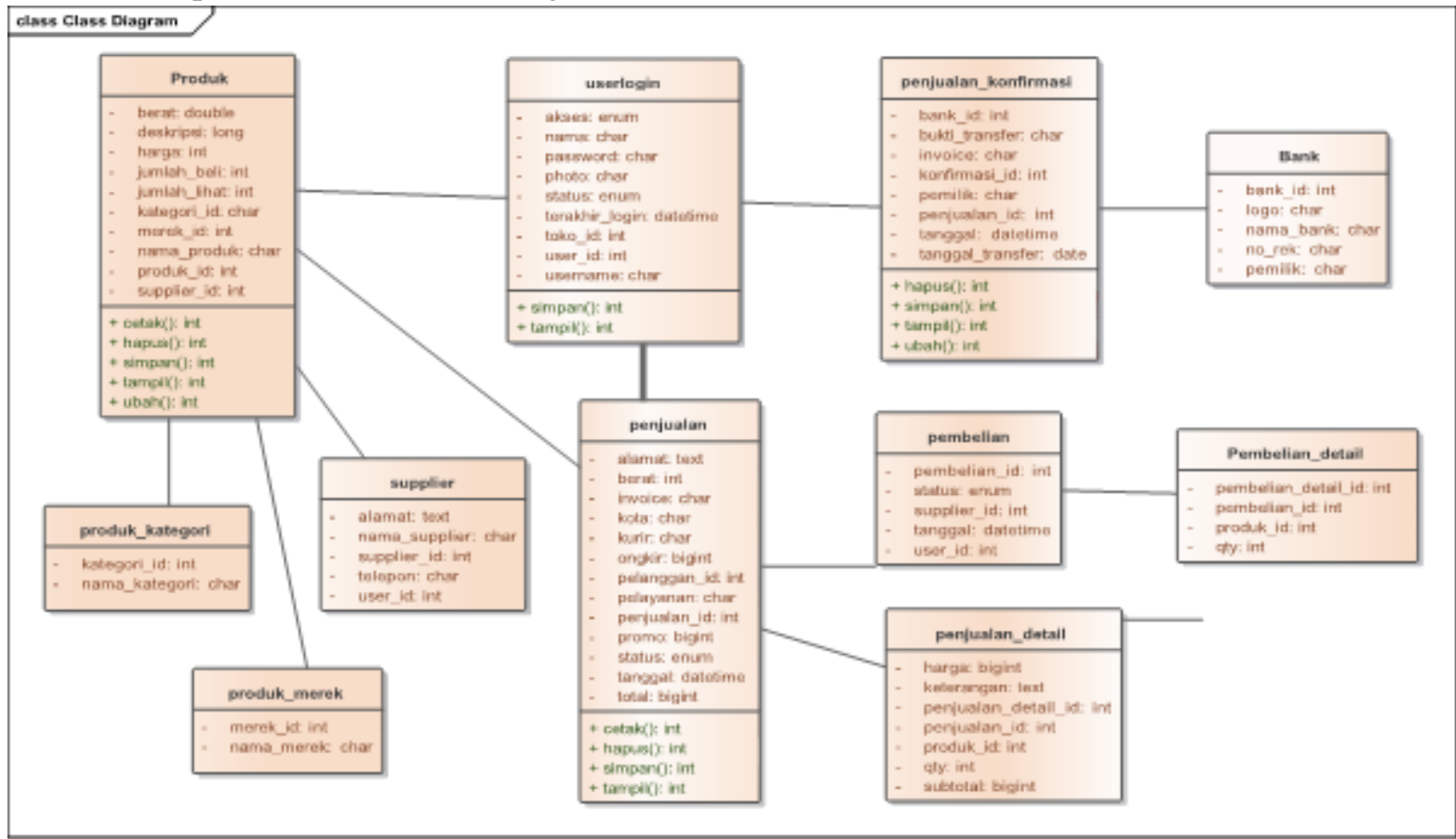

Gambar 8. Class Diagram

\subsection{Implementasi}

Berikut ini merupakan perancangan dari sistem informasi penjualan berbasis web. Terdapat beberapa halaman home pada masing-masing setiap aktor yang tampak seperti berikut:

a. Halaman login

\begin{tabular}{l|l|} 
Username & Username \\
Password & Password \\
\hline & Login \\
\hline
\end{tabular}

Gambar 9. Tampilan halaman Login

b. Halaman home cutomer

SISTEM INFORMASI PENJUALAN

Cindyah Collection

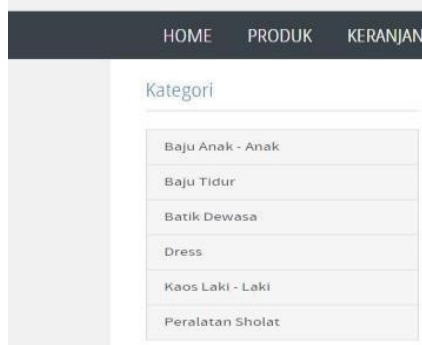

BEST SELLER

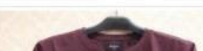

\section{KONFIRMASI PEMBAYARAN TRACKING ORDER INFORMASI}
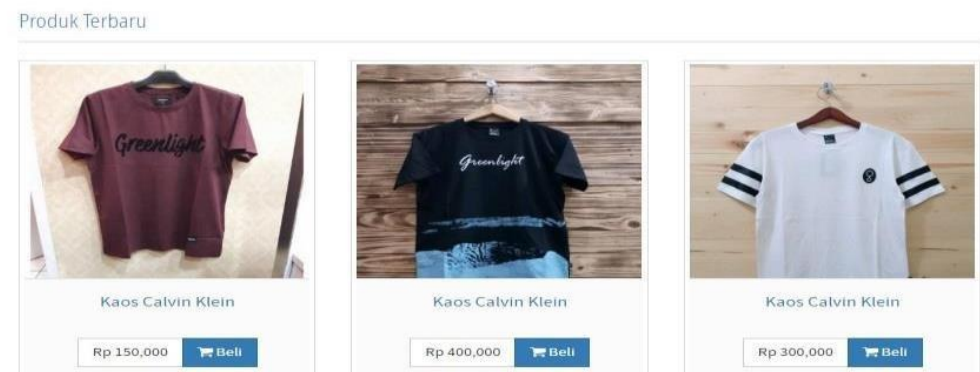

Gambar 10. Tampilan halaman Home Customer 
c. Halaman home manager

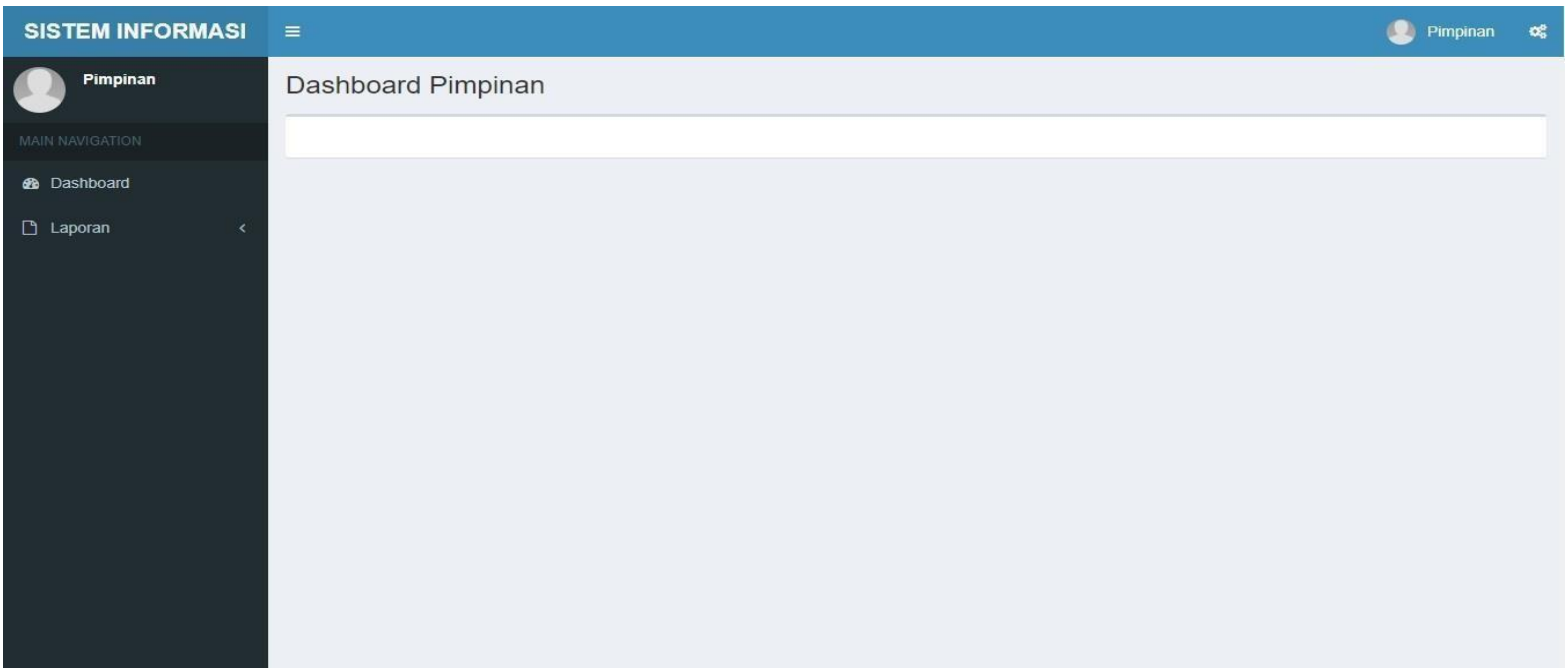

Gambar 11. Tampilan halaman Home Manager

\section{d. Halaman home administrator}

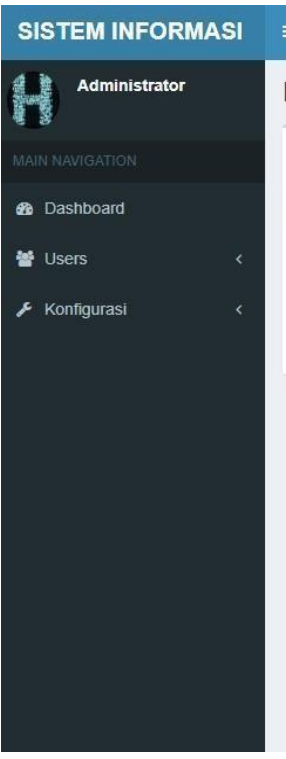

Dashboard Admin

Selamat Datang, Administrator

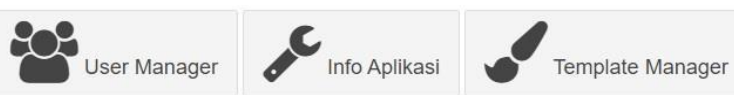

Gambar 12. Tampilan halaman Home Administrator

e. Halaman home operator

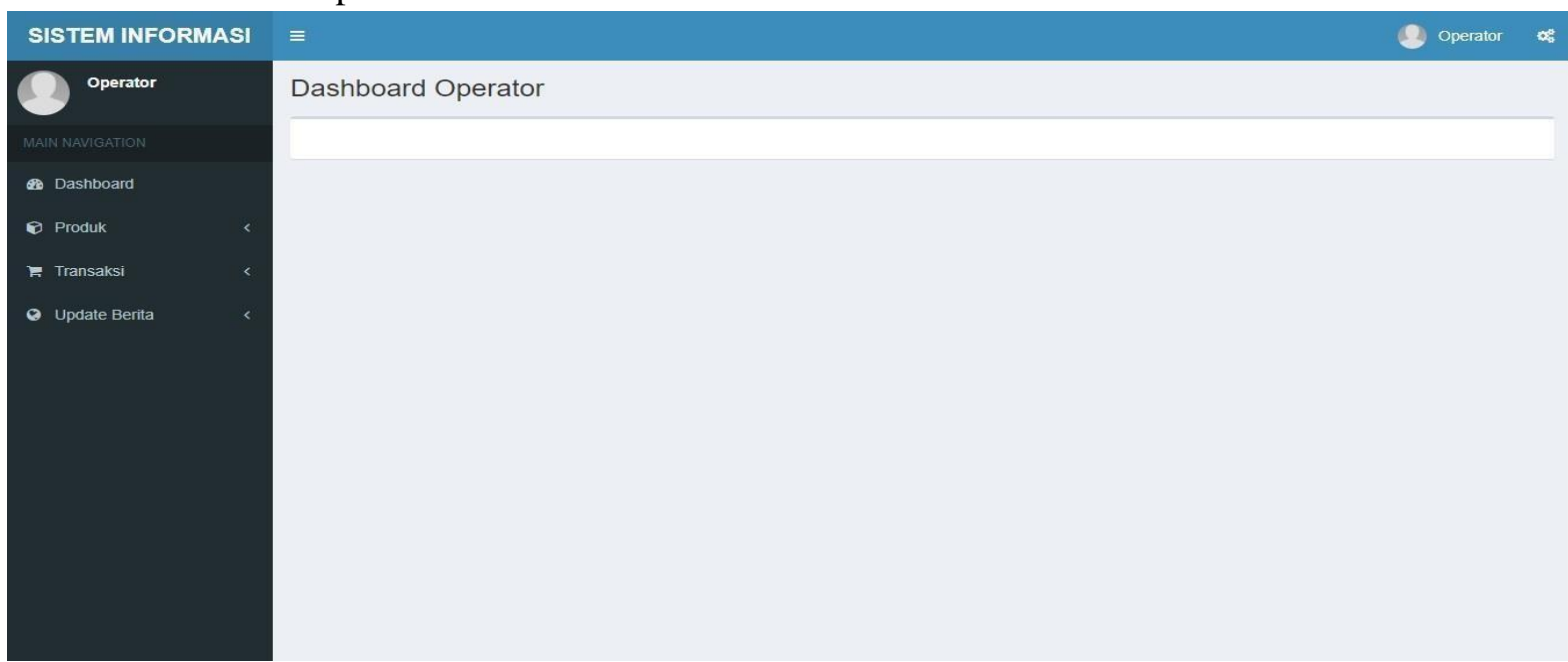

Gambar 13. Tampilan Halaman Home Operator 


\subsection{Pengujian}

Adapun pengujian dilakukan yang tujuanya untuk memperoleh kesalahan yang ada pada sistem. Pengujian dilakukan menggunakan blackbox testing. Dengan menggunakan blackbox testing kita dapat mengetahui keluaran apa yang diharapkan. Pada tabel ini berisi persyaratan fungsional sistem yang pengujianya dilakukan bersama dengan pengguna. Pada tabel dibawah ini juga dapat mengetahui menumenu yang telah disediakan dan cara agar pengguna tidak kebingungan saat melakukan proses pengoperasian saat menggunakan web yang telah dibuat.

Tabel 1. Hasil Pengujian dengan Blackbox

\begin{tabular}{|c|c|c|c|c|}
\hline No & Test Case & Keluaran & Actor & Hasil \\
\hline 1 & Pilih menu login & Tampil menu login & $\begin{array}{l}\text { Customer, } \\
\text { Administrator, } \\
\text { Operator, } \\
\text { Manager }\end{array}$ & Sesuai \\
\hline 2 & $\begin{array}{l}\text { Pilih menu belum } \\
\text { punya akun }\end{array}$ & Tampil menu daftar & Customer & Sesuai \\
\hline 3 & Pilih menu kategori & Tampil kategori produk & Customer & Sesuai \\
\hline 4 & Pilih menu produk & Tampil katalog produk & Customer & Sesuai \\
\hline 5 & Pilih menu beli & Tampil detail produk & Customer & Sesuai \\
\hline 6 & Pilih keranjang & Tampil keranjang belanja & Customer & Sesuai \\
\hline 7 & Pilih selesai belanja & Tampil checkout belanja & Customer & Sesuai \\
\hline 8 & Pilih pembayaran & Tampil tagihan order & Customer & Sesuai \\
\hline 9 & Pilih disini & $\begin{array}{l}\text { Tampil konfirmasi } \\
\text { pembayaran }\end{array}$ & Customer & Sesuai \\
\hline 10 & $\begin{array}{l}\text { Pilih konfirmasi } \\
\text { pembayaran }\end{array}$ & $\begin{array}{l}\text { Tampil konfirmasi } \\
\text { pembayaran }\end{array}$ & Customer & Sesuai \\
\hline 11 & Pilih konfirmasi & Tampil tahap validasi & Customer & Sesuai \\
\hline 12 & Pilih tracking order & Tampil tracking order & Customer & Sesuai \\
\hline 13 & Pilih informasi & Tampil informasi & Customer & Sesuai \\
\hline 14 & Pilih menu daftar & Tampil form pendaftaran & Customer & Sesuai \\
\hline 15 & Pilih daftar & $\begin{array}{l}\text { Tampil pendaftaran } \\
\text { berhasil }\end{array}$ & Customer & Sesuai \\
\hline 16 & Pilih menu sudah punya akun & Tampil menu login & Customer & Sesuai \\
\hline 17 & $\begin{array}{l}\text { Pilih menu } \\
\text { pencarian }\end{array}$ & Tampil form pencarian & Customer & Sesuai \\
\hline 18 & Pilih menu cari & Tampil hasil pencarian & Customer & Sesuai \\
\hline 19 & $\begin{array}{l}\text { Pilih menu akun } \\
\text { saya }\end{array}$ & Tampil menu akun saya & Customer & Sesuai \\
\hline 20 & Pilih menu profil & Tampil profil & Customer & Sesuai \\
\hline 21 & $\begin{array}{l}\text { Pilih menu informasi } \\
\text { tentang kami }\end{array}$ & $\begin{array}{l}\text { Tampil informasi tentang } \\
\text { kami }\end{array}$ & Customer & Sesuai \\
\hline 22 & $\begin{array}{l}\text { Pilih menu informasi } \\
\text { konfirmasi pembayaran }\end{array}$ & $\begin{array}{l}\text { Tampil informasi } \\
\text { konfirmasi pembayaran }\end{array}$ & Customer & Sesuai \\
\hline
\end{tabular}


Tabel 1. Hasil Pengujian dengan Blackbox (lanjutan)

\begin{tabular}{|c|c|c|c|c|}
\hline No & Test Case & Keluaran & Actor & Hasil \\
\hline 23 & $\begin{array}{l}\text { Pilih menu history } \\
\text { belanja }\end{array}$ & Tampil history belanja & Customer & Sesuai \\
\hline 24 & Pilih menu produk & Tampil menu produk & Operator & Sesuai \\
\hline 25 & Pilih menu kategori & Tampil data kategori & Operator & Sesuai \\
\hline 26 & Pilih menu merek & Tampil data merek & Operator & Sesuai \\
\hline 27 & Pilih menu produk & Tampil data produk & Operator & Sesuai \\
\hline 28 & $\begin{array}{l}\text { Pilih menu transaksi } \\
\text { order }\end{array}$ & Tampil data order & Operator & Sesuai \\
\hline 29 & Pilih update berita & Tampil menu update berita & Operator & Sesuai \\
\hline 30 & $\begin{array}{l}\text { Pilih menu semua } \\
\text { halaman }\end{array}$ & $\begin{array}{l}\text { Tampil data semua } \\
\text { halaman }\end{array}$ & Operator & Sesuai \\
\hline 31 & $\begin{array}{l}\text { Pilih menu tambah } \\
\text { halaman }\end{array}$ & $\begin{array}{l}\text { Tampil form tambah } \\
\text { halaman }\end{array}$ & Operator & Sesuai \\
\hline 32 & Pilih menu user & Tampil menu user & Administrator & Sesuai \\
\hline 33 & Pilih menu all user & $\begin{array}{l}\text { Tampil data semua } \\
\text { pengguna }\end{array}$ & Administrator & Sesuai \\
\hline 34 & Pilih menu add user & $\begin{array}{l}\text { Tampil form tambah } \\
\text { pengguna }\end{array}$ & Administrator & Sesuai \\
\hline 35 & Pilih menu konfigurasi & Tampil menu konfigurasi & Administrator & Sesuai \\
\hline 36 & Pilih menu aplikasi & $\begin{array}{l}\text { Tampil form konfigurasi } \\
\text { aplikasi }\end{array}$ & Administrator & Sesuai \\
\hline 37 & Pilih menu tema & $\begin{array}{l}\text { Tampil menu konfigurasi } \\
\text { tema }\end{array}$ & Administrator & Sesuai \\
\hline 38 & Pilih menu laporan & Tampil menu laporan & Manager & Sesuai \\
\hline 39 & Pilih menu penjualan & $\begin{array}{l}\text { Tampil data laporan } \\
\text { penjualan }\end{array}$ & Manager & Sesuai \\
\hline 40 & Pilih menu tampilkan & $\begin{array}{l}\text { Tampil hasil laporan } \\
\text { penjualan }\end{array}$ & Manager & Sesuai \\
\hline 41 & Pilih menu logout & Tampil halaman home & $\begin{array}{c}\text { Customer, } \\
\text { Administrator, } \\
\text { Operator, } \\
\text { Manager }\end{array}$ & Sesuai \\
\hline
\end{tabular}

\section{Kesimpulan}

Dari hasil pembahasan sistem informasi penjualan berbasis web pada Cindyah Collection dapat ditarik sebuah kesimpulan sebagai beikut Sistem informasi penjualan berbasis web ini dapat dijadikan media penjualan oleh Cindyah Collection dan Sistem informasi penjualan berbasis web ini dapat menyimpan data dan memproses penjualan pada Cindyah Collection, selain itu dapat juga melaporkan hasil penjualan tanpa perlu menghitung dengan Microsoft Exel.

Untuk menanggulangi permasalahan dan mencapai lebih baik buat kedepanya maka, saran sebagai berikut pada proses pembayaran masih menggunakan transfer manual melalui Bank, kedepanya diharapkan dapat terverifikasi secara otomatis dalam pembayaranya dan perlu pengembangan aplikasi berbasis android supaya konsumen dapat lebih mudah untuk melakukan transaksi pembelian secara online. 


\section{Ucapan Terima Kasih}

Pada kesempatan ini peneliti sangat banyak berterimakasih kepada Bapak Luqman Junaedi selaku pembimbing yang telah banyak memberikan masukan ataupun komentar agar penulisan ini menjadi baik dan rapi. Selain itu peneliti juga berterima kasih kepada Ibu Tri Asminingdyah selaku pemilik Toko Cindyah Collection yang telah memberikan izin untuk melakukan penelitian ditempat Beliau.

\section{Daftar Pustaka}

Andriani, A. dan Qurniati, E. (2018). Sistem Informasi Penjualan Pada Toko Online Dengan Metode Rapid Application Development (RAD). Journal Speed - Sentra Penelitian Engineering dan Edukasi, 10(3), pp. 49-54.

Hasanudin, M. (2019). Aplikasi E-Commerce Sistem Informasi Penjualan Rolling Door Berbasis Rapid Application Development. Petir, 12(1).

Riandya, K. H. dan A. S. (2012). Rancang Bangun Sistem Informasi Penjualan Barang (Studi Kasus: U.D Cendana Depok Townsquare). Jurnal Sistem Informasi, 4(1), pp. 1-6.

Yusdiardi (2014). Rancang Bangun Sistem Informasi Penjualan (Studi Kasus: PT. I - Cube Creativindo), 1(1), pp. 1-106. 